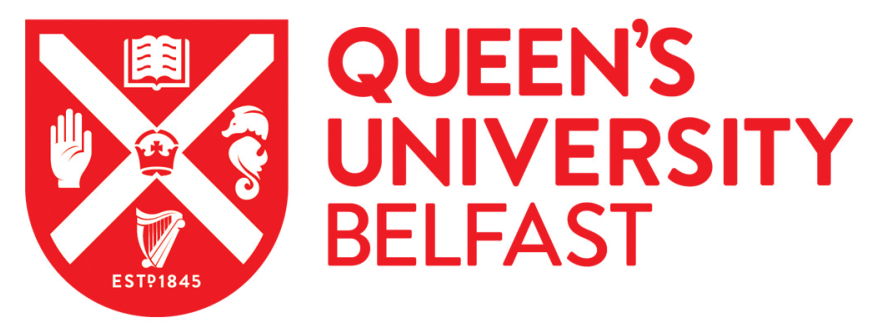

\title{
Adiposity Associated Plasma Linoleic Acid is Related to Demographic, Metabolic Health and Haplotypes of FADS1/2 Genes in Irish Adults
}

Li, K., Brennan, L., Bloomfield, J. F., Duff, D. J., McNulty, B. A., Flynn, A., Walton, J., Gibney, M. J., \& Nugent, A. P. (2018). Adiposity Associated Plasma Linoleic Acid is Related to Demographic, Metabolic Health and Haplotypes of FADS1/2 Genes in Irish Adults. Molecular Nutrition \& Food Research, [1700785]. https://doi.org/10.1002/mnfr.201700785

Published in:

Molecular Nutrition \& Food Research

Document Version:

Peer reviewed version

Queen's University Belfast - Research Portal:

Link to publication record in Queen's University Belfast Research Portal

Publisher rights

(c) 2018 WILEY-VCH Verlag GmbH \& Co.

This work is made available online in accordance with the publisher's policies. Please refer to any applicable terms of use of the publisher.

\section{General rights}

Copyright for the publications made accessible via the Queen's University Belfast Research Portal is retained by the author(s) and / or other copyright owners and it is a condition of accessing these publications that users recognise and abide by the legal requirements associated with these rights.

Take down policy

The Research Portal is Queen's institutional repository that provides access to Queen's research output. Every effort has been made to ensure that content in the Research Portal does not infringe any person's rights, or applicable UK laws. If you discover content in the Research Portal that you believe breaches copyright or violates any law, please contact openaccess@qub.ac.uk. 
Adiposity associated plasma linoleic acid is related to demographic, metabolic health and haplotypes of FADS1/2 genes in Irish adults.

3 Name of Authors: Kaifeng Li $^{1}$, Lorraine Brennan ${ }^{1}$, Jack F. Bloomfield ${ }^{2}$, Dan J. Duff ${ }^{2}$, Breige A.

$4 \quad$ McNulty $^{1}$, Albert Flynn ${ }^{3}$, Janette Walton ${ }^{3,4}$,Michael J. Gibney ${ }^{1}$, Anne P. Nugent ${ }^{1,5^{*}}$.

$5 \quad{ }^{1}$ Institute of Food and Health, School of Agriculture and Food Science, University College Dublin 6 (UCD), Belfield Dublin, Republic of Ireland; ${ }^{2}$ Chemical Analysis Laboratories, Sandycove, 7 Dublin, Republic of Ireland, ${ }^{3}$ School of Food and Nutritional Sciences, University College Cork, 8 Cork, Ireland. ${ }^{4}$ School of Biological Sciences, Cork Institute of Technology, Cork, Ireland. ${ }^{5}$ School of Biological Sciences, Institute for Global Food Security, Queens University Belfast, Northern Ireland.

Address Correspondence: A.P. Nugent, Tel: +353 879864415

Email: anne.nugent@ucd.ie,Address: Institute of Food and Health, University College Dublin (UCD), Belfield, Dublin 4, Republic of Ireland.

Abbreviations: AgRP, agouti-related protein; ARA, arachidonic acid; CVD, cardiovascular disease; CHD, coronary heart disease; D5D: $\Delta$-5-desaturase; D6D, $\Delta$-6-desaturase; DGLA, dihomo- $\gamma$-linoleic acid; DNL, de-novo lipogenesis; FADS, fatty acid desaturase; GLA, $\gamma$-linoleic acid; HOMA-IR , homeostatic model assessment-insulin resistance; hs-CRP, high-sensitivity-Creactive protein; JNK, c-Jun amino-terminal kinases; LA, linoleic acid; LD, linkage disequilibrium; MetS, metabolic syndrome; NANS, National Adult Nutrition Survey; PAI-1, plasminogen activator inhibitor-1; QUICKI, quantitative sensitivity check index; RCT, randomized control trials; SNP, single nucleotide polymorphism; TAG, triacylglycerol; TE, total energy; TLR4, tolllike receptor 4; TNF, tumor necrosis factor. 
Keywords: FADS1, FADS2, genotype, linoleic acid,

\section{Abstract}

Scope: This study examined to what extent plasma linoleic acid (LA) is modified by adiposity, and explored any association between plasma LA, demographics, dietary intakes, markers of metabolic health and haplotypes of the fatty acid desaturase (FADS) $1 / 2$ genes.

Methods and results: 820 participants with fasting blood samples from Irish National Adult Nutrition Survey were studied. Plasma fatty acids were determined using GC-MS. 15 SNPs of FADS $1 / 2$ genes were genotyped. Plasma LA decreased while $\gamma$-linoleic acid and dihomo- $\gamma$ linoleic acid increased in overweight/obese participants $(P \leq 0.002)$. Participants in the highest quartile of plasma LA showed decreased plasma markers of de novo lipogenesis, insulin resistance and of inflammation (TNF- $\alpha$, PAI-1) $(P \leq 0.005)$. Adiposity (waist circumference and body fat) was strongly inversely associated with plasma LA accounting for $11.8 \%$ of variance observed, which was followed by FADS1/2 haplotypes (3.9\%), quantity and quality of carbohydrate intakes (3.8 \%), dietary PUFA intakes (3.7 \%), systolic blood pressure $(3.6 \%)$ and age $(3.2 \%)$.

Conclusion: Plasma LA was inversely associated with adiposity, followed by haplotypes of FADS1/2 genes, carbohydrate intakes and dietary PUFA intakes. The association observed between plasma LA and adiposity may be linked to decreased de novo lipogenesis, insulin resistance and inflammation. 


\section{Introduction}

The essential fatty acid, dietary linoleic acid (LA) has traditionally been considered as protective against cardiovascular disease (CVD) [1] and coronary heart disease (CHD) [2, 3]. Randomized controlled trials suggest that diets high in PUFA may result in lower fat accumulation relative to other fatty acids $[4,5]$. A number of observational studies have also attempted to relate circulating or plasma LA to health outcomes. In healthy adults, two recent studies which completed pattern analysis of a suite of plasma and erythrocyte fatty acids identified patterns rich in LA, both of which were associated with healthier phenotypes $[6,7]$. The Epic Interact Study reported a strong inverse association between plasma linoleic acid and type 2 diabetes incidence [8]. Other studies in older populations or those at risk of CVD have suggested that circulating LA is inversely related to adiposity $[9,10]$, central adiposity $[5,11]$ and risk of the metabolic syndrome and type 2 diabetes, but not CHD $[12,13]$. In a middle-aged community cohort, half of whom were obese, erythrocyte LA was inversely related with insulin resistance measured by HOMA score and IL-6 [11]. However any relationship between plasma LA and health may be influenced by body weight status, with initial reports suggesting that circulating LA is positively related to circulating concentrations of soluble intercellular adhesion molecule-1 in (ICAM, a marker of endothelial activation and predictor of future CVD events) obese participants, the opposite being observed for normal weight adults [6]. Beyond this, little is known in terms of to what extent circulating LA level is associated with adiposity and how circulating LA is related to other markers of inflammation and metabolic health, particularly in younger, healthy cohorts.

The enzymes $\Delta-5$ and $\Delta-6$ desaturase, encoded by fatty acid desaturase (FADS) 1 and 2 genes, are the rate limiting enzymes regulating synthesis of long-chain n-6 polyunsaturated fatty acids (PUFA) such as the conversion of LA to $\gamma$-linoleic acid (GLA, 18:3n-6), dihomo- $\gamma$-linoleic acid (DGLA, 
20:3n-6) and arachidonic acid (ARA, 20:4n-6). Using genotype and haplotype analysis, circulating LA levels were associated with FADS 1 and 2 genes [14-16], with carriers of minor alleles demonstrating increased circulating LA [17]. Generally, the interaction between adiposity, dietary intakes, circulating LA and haplotypes of FADS1/2 genes and how any interaction may affect markers of inflammation and risk of metabolic syndrome (MetS) remain largely unknown. Against this backdrop, the objective of present study was to explore, in a cohort of healthy Irish adults, the association between plasma LA and adiposity, demographics, dietary intakes and haplotypes of FADS1/2 genes.

\section{Participants and methods}

\section{Design and population}

This paper uses data from the cross-sectional national food survey of Irish adults: the National Adult Nutrition Survey (NANS) [18]. The NANS (May 2008-April 2010) examined the habitual food and beverage intake of a representative sample ( $\mathrm{n}=1500,740$ males and 760 females) of Irish adults aged 18-90 years who were free-living and who were not pregnant or breast feeding. Ethical approval was obtained from University College Cork Clinical Research Ethics Committee of the Cork Teaching Hospitals and the Human Ethics Research Committee of University College Dublin (ECM 3 (p) 4 September 2008). All procedures in this study were in accordance with the guidelines laid down in the Declaration of Helsinki, with written informed consent obtained from all participants.

As no national identification system exists in the Republic of Ireland, hence participants were randomly selected from the Data Ireland (National Postal Service) database of free-living adults 
in Ireland in 20 geographical clusters nationwide, with clusters selected to provide proportional representation across the urban-rural continuum and a minimum of 100 participants in the least populated age and sex subgroups. A sample of 1500 free-living adults, representing the Irish population of over 4 million people participated in the dietary survey with analyses of the profile of NANS showing it to be representative of adults in Ireland with respect to age, gender, social class and urban/rural location compared to the most recent Irish census [18-20]. The overall response rate was $60 \%$. In the present paper, only participants for whom fatty acid profiles were available and valid reporters are included, leaving a final sample size of 820 (which remained representative of the entire cohort). Demographics of participants who provided fasting blood samples were reported elsewhere [20].

\section{Dietary assessment}

Food and beverage consumption was assessed using a 4-day semi-weighed food record. Initial nutrient analysis was carried out using the Weighed Intake Software Program (Tinuviel Software, Anglesey UK), which uses data from McCance \& Widdowson's The Composition of Foods, fifth and sixth editions plus all nine supplemental volumes as described elsewhere [18] to generate nutrient intake data. Adjustments were made to the food composition database to take account of recipes, nutritional supplements, commonly consumed generic Irish food and new foods on the market. All entries were double-checked by the researcher and a random sample was checked by another researcher in-house to minimize the chance of error. 
Plasma fatty acids analysis

The procedures used to determine plasma fatty acids profiles in the fasted samples are described elsewhere [6]. In brief, plasma lipids were extracted using the method of Bligh \& Dyer [21]. Butylated hydroxytoluene (BHT) and heptadecanoic acid (2 $\mathrm{mg} / \mathrm{mL}$ in methanol) were used as antioxidant and internal standard, respectively. Extracted plasma lipids were transesterified using boron tri-fluoride-methanol solution (14\%), and the resulting fatty acid methyl esters (FAME) were extracted twice using hexane and water [22]. FAMEs were separated and identified by gas chromatography coupled with mass spectrometry (GC-MS) HP 5890 Series II, HP 5971A (Hewlett Packard) using an Omegawax 250 fused silica capilary column $(30 \mathrm{~m} \times 0.25 \mathrm{~mm} \times 0.25 \mu \mathrm{m}$ film thickness, (Supelco). 38 known peaks were identified (including 17:0 as internal standard) using GC-MS. Laboratory CV of LA in fasting blood samples was $14.4 \%$. The demographics of participants who provided a blood sample ( $76 \%$ of total sample), and those in the entire sample have been reported elsewhere, with no significant differences identified [19].

Assessment of biochemical profiles and metabolic risk factors

Collection of anthropometric measurements (including weighed body weight, BMI, waist circumference, body fat and blood pressure) and biochemistry parameters assessment has been described elsewhere [23, 24]. In brief, anthropometric measurements were carried out in duplicate by trained researchers using standardized methods. \% body fat and weight were collected using Tanita ${ }^{\circledR}$ Model BC-420 MA body composition analyzers (Tanita Ltd. GB) with a \% CV of $0.73 \%$ and $0.02 \%$ respectively. Height was measured using a Leicester portable height measure (Seca, Birmingham, UK). All scales were calibrated and placed on a hard surface prior to use with participants asked to remove any heavy clothing, accessories or shoes as appropriate. Hip and waist 
circumference were measured using non-stretch measuring tape to the nearest $0.1 \mathrm{~cm}$ with $\% \mathrm{CV}$ of $0.17 \%$ and $0.13 \%$ respectively. Weight class was created as normal weight (BMI $<25 \mathrm{~kg} / \mathrm{m}^{2}$ ), overweight (BMI 25-30 kg/m²) and obese (BMI $>30 \mathrm{~kg} / \mathrm{m}^{2}$ ). Blood samples were collected by venepuncture by trained phlebotomists and stored appropriately until they reached the lab within 5 hours of collection for processing and further storage at $-80^{\circ} \mathrm{C}$ until further analysis. Biochemical values were assessed using a clinical bioanalyzer (Randox Daytona, Randox Laboratories) and cytokines and hormones using a biochip array system (Evidence Investigator, Randox Laboratories) except adiponectin which was measured by ELISA (ALPCO Diagnostics Kit). All samples were run in duplicate with standard quality control procedures followed in both analyses to ensure data integrity. Homeostatic model assessment-IR (HOMA-IR) score was calculated using the formula (fasting insulin $\mu \mathrm{U} / \mathrm{mL}$ x fasting glucose $\mathrm{mmol} / \mathrm{L}$ )/22.5 [25]. Quantitative sensitivity check index (QUICKI) score was calculated as follows: $1 /(\log$ (fasting insulin $\mu \mathrm{U} / \mathrm{mL})+\log ($ fasting glucose $\mathrm{mg} / \mathrm{dL})$ [26]. Diagnosis of MetS was defined according to the National Cholesterol Education Programme's Adult Treatment Panel III criteria for MetS 2001 [27] including fasting blood glucose concentrations of 5.5-7.0 mmol/L, serum triacylglycerol (TAG) concentrations of $\geq 1.7$ $\mathrm{mmol} / \mathrm{L}, \mathrm{HDL}<1.0 \mathrm{mmol} / \mathrm{L}$ (men), $<1.3 \mathrm{mmol} / \mathrm{L}$ (women), blood pressure $\geq 130 / 85 \mathrm{mmHg}$ and waist circumference $>102 \mathrm{~cm}$ (men) $\&>88 \mathrm{~cm}$ (women). Physical activity was estimated using a tri axial accelerometer (Actigraph GT1M, ActiGraph, LLC) for the four days of the survey period [28].

\section{Genotyping}

15 single nucleotide polymorphisms (SNPs) were selected based on previous studies which have been shown to be associated with circulating LA [14, 16, 29] and human health [30]. SNP 
genotyping was then conducted by the LGC group (www.lgcgroup.com) using their proprietary KASPar polymerase chain reaction technique [31].

Statistical analysis

Plasma n-6 PUFA (18:2n-6, 18:3n-6, 20:2n-6, 20:3n-6, 20:4n-6, 22:4n-6) profiles were compared across normal weight, over-weight and obese participants. Quartiles of plasma LA, GLA and DGLA were obtained using SPSS version 20.0 (IBM Inc. Chicago, USA). General linear contrast model adjusted for age, body fat, blood pressure, waist circumference, waist hip ratio, smoking status, working energy expenditure, and BMI was applied across plasma LA quartiles for comparison of percentage of plasma fatty acid, nutrient density (calculated as $\%$ total energy (TE) or $\mu \mathrm{g}$ or $\mathrm{mg} / 10 \mathrm{MJ})$, and circulating concentrations of biochemical biomarkers. Differences in gender, social class, smoking habits, contraceptive use and metabolic risk factors across quartiles were compared using Chi-square test. $\Delta$-5-desaturase (D5D) and $\Delta$-6-desaturase (D6D) were estimated using fatty acid product/precursor ratios as following: $\mathrm{D} 6 \mathrm{D}=\mathrm{C} 18: 3 \mathrm{n}-6 / \mathrm{C} 18: 2 \mathrm{n}-6$, and $\mathrm{D} 5 \mathrm{D}=\mathrm{C} 20: 4 \mathrm{n}-6 / \mathrm{C} 20: 3 \mathrm{n}-6$ [32]. Contraceptive use in females was not controlled for in subsequent analysis due to the low proportion (3.5\%) of oral contraceptive users in NANS with no difference in proportions across LA quartiles $(P=0.094)$. One-way ANOVA was also applied across fatty acid clusters for demographic variables including age, BMI, waist circumference, body fat physical activity, waist hip ratio, and blood pressure. Skewed data were log transformed to obtain normalized distribution. Where appropriate in this exploratory analysis, Bonferroni correction was applied by adjusting the p-values by the number of traits in each table. p-values that exceed 1.0 after correction for multiple testing have been marked down to 1.000 . 
Linkage disequilibrium (LD) was assessed using Haploview 4.2 [33], and haplotype blocks were obtained using the Gabriel's definition [34]. Haplotype frequency was estimated using Haplo.Stat 1.7.6 package in R 3.2 (R Foundation for Statistical Computing, Vienna, Austria; ISBN 3-90005107-0; Internet: http://www.R-project.org). Multiple linear regression with stepwise backward selection was used to explore possible determinants of plasma LA status. Demographic and dietary intake variables were included in the initial model and haplotypes were included in the final model regardless of the significance. Partial $\mathrm{R}^{2}$ was used to calculate the explained variation of each determinants in the final model. The association between plasma LA and haplotypes were estimated using HapStat 3.0 [35].

\section{Results}

A complete fasting plasma fatty acid dataset of 820 participants (mean age $41.9 \pm 16.7$ years, with 412 males and 408 females) were included in the analysis. Initial examination showed that plasma LA and estimated $\Delta$-5-desaturase activity decreased while GLA, DGLA, and $\Delta$-6-desaturase activity increased across the body weight categories in Irish adults $(P \leq 0.003)$ (Table 1). Demographics and markers of metabolic health were compared across the quartiles of plasma LA (Table 2 and Table 3), GLA and DGLA (Table S1) to explore any association between plasma LA, GLA, DGLA and health parameters. As quartiles of plasma LA showed greater separation in terms of demographics and markers of metabolic health (as described below) therefore subsequent analysis focused on plasma LA only. 
As shown in Table 2, participants in the highest quartile of plasma LA displayed a healthier phenotype. Compared with participants in quartile $1(\mathrm{Q} 1)$, participants in quartile $4(\mathrm{Q} 4)$ were younger (50.7 years vs. 36.5 years, $P<1.9 \times 10^{-19}$ ), with lower adiposity (including BMI, body fat, waist circumference and waist hip ratio, $\left.P<3.1 \times 10^{-6}\right)$, blood pressure $(131.9 / 81.4 \mathrm{mmHg}$ vs. 118.2/75.3 mmHg, $\left.P<2.2 \times 10^{-7}\right)$, metabolic risk and a lower proportion were overweight $(45.3 \%$ vs. $32.1 \%)$ or obese $(34.7 \%$ vs. $14.0 \%)\left(P \leq 2.7 \times 10^{-7}\right)$. Higher work activity energy expenditure was observed for Q4 (47.8 MET hrs/wk vs. 66.1 MET hrs/wk, $P<0.026)$ and a greater proportion of participants that never smoked $(41.9 \%$ vs. $62.7 \%, P<0.001)$. Dietary intakes across the quartiles of plasma LA are shown in Table S2. Across plasma LA quartiles, intake of starch, PUFA, n-6 PUFA and dietary fibre significantly increased $(P<0.003)$.

Markers of metabolic health and plasma fatty acids

The clinical chemistry biomarkers and plasma fatty acid levels across quartiles are shown in Table 3. After adjustment for confounders, insulin, C-peptide, TAG, HOMA-IR, PAI-1, TNF- $\alpha$, hs-CRP decreased, while QUICKI and adiponectin increased across plasma LA quartiles $(P \leq 0.005)$. Regarding plasma fatty acids related to the n-6 PUFA pathway, 20:2n-6, 18:3n-6, 20:3n-6 and D6D decreased across plasma LA quartiles $(P \leq 0.019)$, whereas total $n-6$ PUFA and $n-6 / n-3$ ratio increased $\left(P \leq 1.4 \times 10^{-138}\right)$. Plasma total SFA and total MUFA decreased $\left(P \leq 1.1 \times 10^{-21}\right)$, as did plasma fatty acids related to de novo lipogenesis (DNL, including 14:0, 14:1n-5, 16:0, 16:1n-7 and 18:1n-9) were also significantly decreased $\left(P \leq 4.7 \times 10^{-6}\right)$ across plasma LA quartiles. 
Effects of haplotypes on plasma n-6 PUFA profiles

The degree of LD between the analyzed genetic polymorphisms are shown in Figure S1. Haplotypes were statistically reconstructed for three windows (Table 4). The first window contained all 15 SNPs from rs174537 to rs482548. Seven haplotypes were identified in this window with a frequency over $1 \%$, of which haplo 7 was the most common (53.9\%) haplotype with no minor allele. Compared with haplo 7 , haplo 1, 3, 4, 5 were positively associated with plasma LA $(P \leq 0.02)$, with all of the haplotypes except haplo 2 negatively associated with D5D and D6D $\left(P \leq 6.44 \times 10^{-3}\right)$ (Table 5). The second window contained 8 SNPs from rs 174537 to rs99780, and four haplotypes were reconstructed with frequency above $1 \%$. Compared with the most common haplotype (haplo 4 with frequency of $65.6 \%$ ) in the second window, all the other haplotypes were positively associated with plasma LA while negatively associated with D5D and D6D $\left(P \leq 1.67 \times 10^{-3}\right)$. The third window contained 3 SNPs from rs2524299 to rs174583, and three haplotypes were reconstructed with a frequency above $1 \%$. Compared with the most common haplotype (haplo 3 with frequency of $65.5 \%$ ) in the third window, all of the other haplotypes were positively associated with plasma LA while negatively associated with D5D and D6D $(P \leq$ $\left.1.64 \times 10^{-3}\right)$. Haplotypes in the second and third windows explained the variance of plasma LA by $3.5 \%$, respectively (Table S2 and Table S4). We also explored the interaction of dietary PUFA intakes and haplotypes but no significant interaction was found after adjustment for confounders $(P \geq 0.057)$.

\section{Possible determinants of plasma LA}

Multiple linear regression of possible determinants of plasma LA are shown in Table 6. Of the variables tested, adiposity measures (waist circumference and body fat) were most strongly 
inversely associated with plasma LA accounting for $11.8 \%$ of the total variance, followed by 15 SNP haplotypes (3.9\%), quantity and quality of carbohydrate intakes $(3.8 \%)$, dietary PUFA intakes (3.7\%), systolic blood pressure (3.6\%) and age (3.2\%).

\section{Discussion}

In this study, higher plasma LA was related to a healthier phenotype and metabolic profile in Irish adults. We observed an inverse relationship between plasma LA and the adiposity measures studied, with waist circumference and body fat most strongly associated with plasma LA, followed by dietary PUFA and haplotypes of FADS genes. The beneficial effects of plasma LA may be associated with decreased biomarkers of DNL, insulin resistance and inflammation, all of which have previously been linked with the pathogenesis of obesity [36, 37].

A growing body of evidence suggests that LA may influence health outcomes. An inverse relationship between serum LA and all-cause mortality (but not CVD risk) has been described in a cohort of healthy older adults [38]. Further observational studies report lower plasma phospholipid LA and higher GLA and DGLA levels in overweight/obese adolescents [9, 39] and higher proportions of serum and cholesterol ester LA being associated with lower markers of abdominal obesity and BMI and reduced T2D incidence [8, 40-42]. Altered desaturase activity is documented in overweight and obese participants and those with T2D, with reports of elevated D6D and decreased D5D [8, 9, 39, 41]. Growing evidence suggests that such benefits may arise from effects of LA on body fat accumulation. Animal trials and human RCTs indicate that compared to SFA, high LA intakes result in improvements in body composition outcomes $[4,5$, 43]. There is some evidence of similar benefits in populations with regular dietary LA intakes whereby serum or erythrocyte LA was inversely related to body fat, specifically trunk fat in a 
healthy elderly cohort [5] and in a middle aged relatively healthy cohort [11]. Of interest, such benefits were not observed for erythrocyte n-3 PUFA or for the MUFA, OA [11]. In the present study, we confirm these fatty acid profiles of elevated LA and altered patterns of D5D and D6D activity according to body weight status and without significant alterations in n-3 PUFA status, in this nationally representative cohort of healthy adults aged 18-90 y. Our study adds to evidence which is suggestive of either a protective effect of circulating LA on obesity and/or, of altered fatty acid metabolism in the presence of excess body weight. However, desaturase activities based on ratio of circulating fatty acids are indirect measure of enzyme activities which may also be affected by lifestyle. Further, our results are presented as percentage, rather than absolute, values which may imply co-dependence on all other fatty acids. Further research is required to explore the specific health implications of plasma LA as well as any interactions between dietary PUFA intakes and circulating fatty acid profiles.

Previous studies have demonstrated a similar inverse association between circulating LA and biomarkers such as insulin, glucose, TAG, hs-CRP, with higher adiponectin concentrations and with reduced risk of insulin resistance, metabolic syndrome, cardio-metabolic risk score and T2D [5, 8-10, 44-46]. In addition, our results show decreased inflammation markers such as PAI-1 and TNF- $\alpha$ across plasma LA quartiles, elevated levels of which have been linked to obesity [47]. Nevertheless, this decrease in markers of metabolic health in the present study remained significant even when controlling for BMI and waist circumference. A negative association between plasma LA and inflammation markers e.g. IL-6 and CRP has been reported elsewhere $[11,48]$. Such associations may be explained by a recent study, showing that LA may suppress the expression of toll-like receptor 4 (TLR4), phosphorylation levels of c-Jun amino-terminal kinases (JNK) and agouti-related protein (AgRP) [49]. AgRP promotes food intake[50], and an absence of JNK1 may 
lead to decreased adiposity and improved insulin sensitivity [51]. Such potential mechanisms may help explain the decreased adiposity and markers of inflammation observed in participants in the highest quartile of plasma LA (Q4). Moreover, bioactive metabolites of LA such as nitro-linoleic acid may be anti-inflammatory by reducing the activation and gene transcription of nuclear factor$\kappa \mathrm{B}$ while stimulating activation of peroxisome proliferator-activated receptor $\gamma$ [52]. Further research is required in this area.

It is possible that the decreased plasma LA observed in overweight/obese participants in our study may be linked to DNL. DNL is a, typically inhibited, pathway of converting excess carbohydrate to esterified fatty acids which are subsequently stored as TAG in the liver and adipose tissue [53]. Increased DNL has been observed in the obese [36, 54], in non-alcoholic fatty liver disease [55] and under conditions of insulin resistance, including inflammation [53]. Further, DNL stimulated hepatic TAG are reported to be enriched with palmitic acid while depleted in LA [56]. In our study, in addition to decreased levels of plasma LA observed in obese participants, all adults in the lowest quartile of plasma LA had a fatty acid profile suggestive of DNL (i.e. reduced LA, increased 14:0, 16:0, 16:1n-7) and with patterns of biochemical markers suggestive of insulin resistance and lowgrade inflammation. Dietary intakes may also influence DNL, whereby high carbohydrate, low fat diets may promote DNL, particularly when dietary sugar is substituted for starch [57]. In contrast high dietary fibre intakes can yield less short-chain fatty acids, which may suppress DNL and improve insulin sensitivity $[58,59]$. In our study, participants had a relatively high fat diet (mean daily intake of $33.8 \% \mathrm{TE}$ ) and moderate carbohydrate intakes (mean daily intake of 42.6\%TE). Nevertheless, participants with the lowest circulating plasma concentrations (quartile 1) had lower intakes of starch and dietary fibre, while regression analysis identified quantity and quality of carbohydrate intake as the third largest determinant of plasma LA (3.8\%). Collectively, 
in this cohort of generally healthy adults there exists a group with lipid and metabolic profiles suggestive of possible future risk and who can be easily identified by nature of circulating plasma LA concentrations. This is supportive of the hypothesis which aims to clarify whether endogenous metabolites or lipids constitute simple and effective biomarkers of metabolic diseases such as NAFLD, type 2 diabetes and metabolic syndrome $[6,55]$.

Polymorphism and haplotype of FADS1/2 genes have been reported to be linked to long-chain PUFA concentrations/metabolism such as for LA, ARA, D5D and D6D [14, 30, 60, 61]. To our knowledge, only one study reported variation of haplotypes of FADS genes in relation to serum phospholipid, which was higher compared with the present study (9.2\% vs. $3.9 \%)$ [14]. This may due to different SNPs, lipid fractions and study population included. Potential dietary PUFA intakes $\times$ haplotypes interactions were also explored in the present study, however, the $\mathrm{P}$ values were above the significant threshold $(P \geq 0.057)$ after adjustment for confounders [62]. The impact of dietary intakes $\times$ haplotypes/genotype interactions on circulating $n-6$ PUFA profiles have been poorly explored and merits future study [63]. Haplotype analysis of FADS genes also revealed significant association between haplotypes and concentration of hs-CRP and TAG $[15,16]$. Similarly, results of genome-wide association studies reported that carriers of the minor allele of rs 174537 and rs 174547 showed lower total cholesterol HDL-C and LDL-C [64, 65]. However, no significant association was identified in our study between haplotypes and inflammation markers, suggesting that haplotype may not be involved in the association between plasma LA and inflammation.

The major strength of the present study is that we included a comprehensive group of inflammation markers, genotype information as well as the combination of dietary and plasma fatty acid data which clearly showed the beneficial effects of a higher plasma LA. Limitations of the study include 
the observational study design that is unable to reveal the causality of the relations. In this national food consumption survey (NANS), body composition measurements were collected by trained field workers with body fat assessed using a Tanita ${ }^{\circledR}$ body fat analyser rather than gold standard methods such as magnetic resonance imaging, computed tomography or DEXA scans. This was due to the practical simplicity of using Tanita ${ }^{\circledR}$ as part of a national food consumption survey. It has been reported that Tanita ${ }^{\circledR}$ is not associated with a clinically significant decrement in performance relative to traditional impedence devices [66] although it is recognized that this technique may slightly overestimate fat mass relative to DEXA [67] and MRI [68]. A further limitation of this study was the use of total plasma fatty acids rather than lipid fractions given that different associations have been reported between phospholipid and cholesterol esters [69]. Finally, we acknowledge that alterations in proportions of circulating fatty acids with age are well described, with reductions in erythrocyte concentrations of linoleic acid reported to be in the order of 2 percentage points per decade [70]. In our study, those in the lowest quartile of plasma LA were older than those in the highest quartile. Hence, it is possible that age-related influences on body fat accumulation and on metabolic health may have influenced outcome. However, we controlled for age in all relevant analysis to attempt mitigate any such risk.

In conclusion, our results showed that plasma LA was inversely associated with adiposity, followed by haplotype of FADS genes and dietary intakes. A higher plasma LA profile was related to a healthier phenotype and markers of metabolic health even when controlling for BMI and waist circumference. Future work is needed to better understand the mechanism of obesity modified plasma LA profile on human health. 
This research was funded by the Irish Department of Agriculture, Food and the Marine and the Health Research Board under their joint Food for Health Research Initiative (2007-12) (grant number FHRIUCC2). Mr. Li is in receipt of a PhD student from the China Scholarship Council 2012-2016.

\section{Author's contribution}

1) designed research: A.P. Nugent, L. Brennan, M.J. Gibney, B.A. McNulty, A. Flynn, J. 


\section{References}

[1] Harris, W. S., Mozaffarian, D., Rimm, E., Kris-Etherton, P., Rudel, L. L., Appel, L. J., Engler, M. M., Engler, M. B., Sacks, F., Omega-6 fatty acids and risk for cardiovascular disease: A science advisory from the American Heart Association nutrition subcommittee of the council on nutrition, physical activity, and metabolism; council on cardiovascular nursing; and council on epidemiology and prevention. Circulation 2009, 119, 902-907.

[2] Farvid, M. S., Ding, M., Pan, A., Sun, Q., Chiuve, S. E., Steffen, L. M., Willett, W. C., Hu, F. B., Dietary linoleic acid and risk of coronary heart disease: a systematic review and meta-analysis of prospective cohort studies. Circulation 2014, 130, 1568-1578.

[3] Oh, K., Hu, F. B., Manson, J. E., Stampfer, M. J., Willett, W. C., Dietary fat intake and risk of coronary heart disease in women: 20 years of follow-up of the nurses' health study. Am J Epidemiol 2005, 161, 672-679.

[4] Bjermo, H., Iggman, D., Kullberg, J., Dahlman, I., Johansson, L., Persson, L., Berglund, J., Pulkki, K., Basu, S., Uusitupa, M., Rudling, M., Arner, P., Cederholm, T., Ahlstrom, H., Riserus, U., Effects of n-6 PUFAs compared with SFAs on liver fat, lipoproteins, and inflammation in abdominal obesity: a randomized controlled trial. Am J Clin Nutr 2012, 95, 1003-1012.

[5] Rosqvist, F., Bjermo, H., Kullberg, J., Johansson, L., Michaëlsson, K., Ahlström, H., Lind, L., Risérus, U., Fatty acid composition in serum cholesterol esters and phospholipids is linked to visceral and subcutaneous adipose tissue content in elderly individuals: a cross-sectional study. Lipids Health Dis 2017, 16, 68.

[6] Li, K., Brennan, L., McNulty, B. A., Bloomfield, J. F., Duff, D. J., Devlin, N. F. C., Gibney, M. J., Flynn, A., Walton, J., Nugent, A. P., Plasma fatty acid patterns reflect dietary habits and metabolic health: a cross-sectional study. Mol Nutr Food Res 2016, 60, 2043-52. 
[7] Bigornia, S. J., Lichtenstein, A. H., Harris, W. S., Tucker, K. L., Associations of erythrocyte fatty acid patterns with insulin resistance. Am J Clin Nutr 2016, 103, 902-909.

[8] Forouhi, N. G., Imamura, F., Sharp, S. J., Koulman, A., Schulze, M. B., Zheng, J., Ye, Z., Sluijs, I., Guevara, M., Huerta, J. M., Kröger, J., Wang, L. Y., Summerhill, K., Griffin, J. L., Feskens, E. J. M., Affret, A., Amiano, P., Boeing, H., Dow, C., Fagherazzi, G., Franks, P. W., Gonzalez, C., Kaaks, R., Key, T. J., Khaw, K. T., Kühn, T., Mortensen, L. M., Nilsson, P. M., Overvad, K., Pala, V., Palli, D., Panico, S., Quirós, J. R., Rodriguez-Barranco, M., Rolandsson, O., Sacerdote, C., Scalbert, A., Slimani, N., Spijkerman, A. M. W., Tjonneland, A., Tormo, M.-J., Tumino, R., van der A, D. L., van der Schouw, Y. T., Langenberg, C., Riboli, E., Wareham, N. J., Association of Plasma Phospholipid n-3 and n-6 Polyunsaturated Fatty Acids with Type 2 Diabetes: The EPIC-InterAct Case-Cohort Study. PLoS Med 2016, 13, e1002094.

[9] Steffen, L. M., Vessby, B., Jacobs, D. R., Jr., Steinberger, J., Moran, A., Hong, C. P., Sinaiko, A. R., Serum phospholipid and cholesteryl ester fatty acids and estimated desaturase activities are related to overweight and cardiovascular risk factors in adolescents. Int J Obes 2008, 32, 1297 1304.

[10] Steffen, B. T., Steffen, L. M., Tracy, R., Siscovick, D., Hanson, N. Q., Nettleton, J., Tsai, M. Y., Obesity modifies the association between plasma phospholipid polyunsaturated fatty acids and markers of inflammation: the Multi-Ethnic Study of Atherosclerosis. Int J Obes 2012, 36, 797-804. [11] Belury, M. A., Cole, R. M., Bailey, B. E., Ke, J. Y., Andridge, R. R., Kiecolt-Glaser, J. K., Erythrocyte linoleic acid, but not oleic acid, is associated with improvements in body composition in men and women. Mol Nutr Food Res 2016, 60, 1206-1212.

[12] Matthan, N. R., Ooi, E. M., Van Horn, L., Neuhouser, M. L., Woodman, R., Lichtenstein, A. H., Plasma phospholipid fatty acid biomarkers of dietary fat quality and endogenous metabolism 
predict coronary heart disease risk: a nested case-control study within the Women's Health Initiative observational study. J Am Heart Assoc 2014, 3.

[13] Chowdhury, R., Warnakula, S., Kunutsor, S., Crowe, F., Ward, H. A., Johnson, L., Franco, O. H., Butterworth, A. S., Forouhi, N. G., Thompson, S. G., Khaw, K. T., Mozaffarian, D., Danesh, J., Di Angelantonio, E., Association of dietary, circulating, and supplement fatty acids with coronary risk: A systematic review and meta-analysis. Ann Int Med 2014, 160, 398-406.

[14] Schaeffer, L., Gohlke, H., Müller, M., Heid, I. M., Palmer, L. J., Kompauer, I., Demmelmair, H., Illig, T., Koletzko, B., Heinrich, J., Common genetic variants of the FADS1 FADS2 gene cluster and their reconstructed haplotypes are associated with the fatty acid composition in phospholipids. Hum Mol Genet 2006, 15, 1745-1756.

[15] Martinelli, N., Girelli, D., Malerba, G., Guarini, P., Illig, T., Trabetti, E., Sandri, M., Friso, S., Pizzolo, F., Schaeffer, L., Heinrich, J., Pignatti, P. F., Corrocher, R., Olivieri, O., FADS genotypes and desaturase activity estimated by the ratio of arachidonic acid to linoleic acid are associated with inflammation and coronary artery disease. Am J Clin Nutr 2008, 88, 941-949.

[16] Bokor, S., Dumont, J., Spinneker, A., Gonzalez-Gross, M., Nova, E., Widhalm, K., Moschonis, G., Stehle, P., Amouyel, P., De Henauw, S., Molnàr, D., Moreno, L. A., Meirhaeghe, A., Dallongeville, J., Group, o. b. o. t. H. S., Single nucleotide polymorphisms in the FADS gene cluster are associated with delta- 5 and delta- 6 desaturase activities estimated by serum fatty acid ratios. J Lipid Res 2010, 51, 2325-2333.

[17] O'Neill, C. M., Minihane, A.-M., The impact of fatty acid desaturase genotype on fatty acid status and cardiovascular health in adults. Proc Nutr Soc 2016, 1-12. 
[18] Li, K., B. A. M., Ann M. Tiernery, Niamh F.C. Devlin, Triona Joyce, Joao C. Leite, Albert Flynn, Janette Walton, Lorraine Brennan, Michael J. Gibney, Anne P. Nugent, Dietary fat intakes in Irish adults in 2011: how much has changed in 10 years? Br J Nutr 2016, 115, 1798-809.

[19] Hopkins, S. M., Gibney, M. J., Nugent, A. P., McNulty, H., Molloy, A. M., Scott, J. M., Flynn, A., Strain, J., Ward, M., Walton, J., McNulty, B. A., Impact of voluntary fortification and supplement use on dietary intakes and biomarker status of folate and vitamin B-12 in Irish adults. Am J Clin Nutr 2015, 101, 1163-72.

[20] Cashman, K. D., Muldowney, S., McNulty, B., Nugent, A., Fitzgerald, A. P., Kiely, M., Walton, J., Gibney, M. J., Flynn, A., Vitamin D status of Irish adults: Findings from the National Adult Nutrition Survey. Br J Nutr 2013, 109, 1248-1256.

[21] Bligh, E. G., Dyer, W. J., A rapid method of total lipid extraction and purification. Canadian J Biochem and Physiol 1959, 37, 911-917.

[22] Eder, K., Gas chromatographic analysis of fatty acid methyl esters. J Chromatography B: Biomed Applications 1995, 671, 113-131.

[23] Boylan, E. A., McNulty, B. A., Walton, J., Flynn, A., Nugent, A. P., Gibney, M. J., The prevalence and trends in overweight and obesity in Irish adults between 1990 and 2011. Public Health Nutr 2014, 17, 2389-97.

[24] O'Donovan, C. B., Walsh, M. C., Nugent, A. P., McNulty, B., Walton, J., Flynn, A., Gibney, M. J., Gibney, E. R., Brennan, L., Use of metabotyping for the delivery of personalised nutrition. Mol Nutr Food Res 2015, 59, 377-385.

[25] Matthews, D. R., Hosker, J. P., Rudenski, A. S., Naylor, B. A., Treacher, D. F., Turner, R. C., Homeostasis model assessment: insulin resistance and beta-cell function from fasting plasma glucose and insulin concentrations in man. Diabetologia 1985, 28, 412-419. 
[26] Katz, A., Nambi, S. S., Mather, K., Baron, A. D., Follmann, D. A., Sullivan, G., Quon, M. J., Quantitative insulin sensitivity check index: A simple, accurate method for assessing insulin sensitivity in humans. J Clin Endocrinol Metab 2000, 85, 2402-2410.

[27] Expert Panel on Detection, E., and Treatment of High Blood Cholesterol in Adults, Executive summary of the third report of the national cholesterol education program (ncep) expert panel on detection, evaluation, and treatment of high blood cholesterol in adults (adult treatment panel iii). JAMA 2001, 285, 2486-2497.

[28] Irish Universities Nutrition Alliance. National Adult Nutrition Survey Summary Report. Cork: Irish Universities Nutrition Alliance. 2011. Internet: http://www.iuna.net/?p=106 2012. (accessed 16/08/2017).

[29] Martinelli, N., Girelli, D., Malerba, G., Guarini, P., Illig, T., Trabetti, E., Sandri, M., Friso, S., Pizzolo, F., Schaeffer, L., Heinrich, J., Pignatti, P. F., Corrocher, R., Olivieri, O., FADS genotypes and desaturase activity estimated by the ratio of arachidonic acid to linoleic acid are associated with inflammation and coronary artery disease. Am J Clin Nutr 2008, 88, 941-949.

[30] Merino, D. M., Ma, D. W., Mutch, D. M., Genetic variation in lipid desaturases and its impact on the development of human disease. Lipids Health Dis 2010, 9, 63.

[31] Ryan, M. F., O'Grada, C. M., Morris, C., Segurado, R., Walsh, M. C., Gibney, E. R., Brennan, L., Roche, H. M., Gibney, M. J., Within-person variation in the postprandial lipemic response of healthy adults. Am J Clin Nutr 2013, 97, 261-267.

[32] Nakamura, M. T., Nara, T. Y., Structure, function, and dietary regulation of delta6, delta5, and delta9 desaturases. Ann Re. Nutr, 2004, 24, 345-76

[33] Barrett, J. C., Fry, B., Maller, J., Daly, M. J., Haploview: analysis and visualization of LD and haplotype maps. Bioinformatics 2005, 21, 263-265. 
490

491

492

493

494

495

496

497

498

499

500

501

502

503

504

505

506

507

508

509

510

511

[34] Gabriel, S. B., Schaffner, S. F., Nguyen, H., Moore, J. M., Roy, J., Blumenstiel, B., Higgins, J., DeFelice, M., Lochner, A., Faggart, M., Liu-Cordero, S. N., Rotimi, C., Adeyemo, A., Cooper, R., Ward, R., Lander, E. S., Daly, M. J., Altshuler, D., The structure of haplotype blocks in the human genome. Science 2002, 296, 2225-2229.

[35] Lin, D., Zeng, D., Millikan, R., Maximum likelihood estimation of haplotype effects and haplotype-environment interactions in association studies. Genet Epidemiol 2005, 29, 299.

[36] Kusunoki, J., Kanatani, A., Moller, D. E., Modulation of fatty acid metabolism as a potential approach to the treatment of obesity and the metabolic syndrome. Endocrine 2006, 29, 91-100.

[37] Winer, Daniel A., Luck, H., Tsai, S., Winer, S., The Intestinal Immune System in Obesity and Insulin Resistance. Cell Metab 2016, 23, 413-426.

[38] Marklund, M., Leander, K., Vikström, M., Laguzzi, F., Gigante, B., Sjögren, P., Cederholm, T., de Faire, U., Hellénius, M.-L., Risérus, U., Polyunsaturated Fat Intake Estimated by Circulating Biomarkers and Risk of Cardiovascular Disease and All-Cause Mortality in a Population-Based Cohort of 60-Year-Old Men and Women. Circulation 2015, 132, 586-94.

[39] Klein-Platat, C., Drai, J., Oujaa, M., Schlienger, J. L., Simon, C., Plasma fatty acid composition is associated with the metabolic syndrome and low-grade inflammation in overweight adolescents. Am J Clin Nutr 2005, 82, 1178-1184.

[40] Warensjo, E., Sundstrom, J., Lind, L., Vessby, B., Factor analysis of fatty acids in serum lipids as a measure of dietary fat quality in relation to the metabolic syndrome in men. Am J Clin Nutr 2006, 84, 442-448.

[41] Alsharari, Z. D., Risérus, U., Leander, K., Sjögren, P., Carlsson, A. C., Vikström, M., Laguzzi, F., Gigante, B., Cederholm, T., De Faire, U., Hellénius, M.-L., Marklund, M., Serum Fatty Acids, 
Desaturase Activities and Abdominal Obesity - A Population-Based Study of 60-Year Old Men and Women. PloS One 2017, 12, e0170684.

[42] Zheng, Z.J., Folsom, A. R., Ma, J., Arnett, D. K., McGovern, P. G., Eckfeldt, J. H., Plasma fatty acid composition and 6-year incidence of hypertension in middle-aged adults: the Atherosclerosis Risk in Communities (ARIC) Study. Am J Epidemiol 1999, 150, 492-500.

[43] Norris, L. E., Collene, A. L., Asp, M. L., Hsu, J. C., Liu, L. F., Richardson, J. R., Li, D., Bell, D., Osei, K., Jackson, R. D., Comparison of dietary conjugated linoleic acid with safflower oil on body composition in obese postmenopausal women with type 2 diabetes mellitus. Am J Clin Nutr 2009, 90, 468-76.

[44] Mayneris-Perxachs, J., Guerendiain, M., Castellote, A. I., Estruch, R., Covas, M. I., Fitó, M., Salas-Salvadó, J., Martínez-González, M. A., Aros, F., Lamuela-Raventós, R. M., López-Sabater, M. C., Plasma fatty acid composition, estimated desaturase activities, and their relation with the metabolic syndrome in a population at high risk of cardiovascular disease. Clin Nutr 2014, 33, 90 97.

[45] Venalainen, T., Agren, J., Schwab, U., de Mello, V. D., Eloranta, A. M., Laaksonen, D. E., Lindi, V., Lakka, T. A., Cross-sectional associations of plasma fatty acid composition and estimated desaturase and elongase activities with cardiometabolic risk in Finnish children-The PANIC study. J Clin Lipidol 2016, 10, 82-91.

[46] Enzenbach, C., Kroger, J., Zietemann, V., Jansen, E. H., Fritsche, A., Doring, F., Boeing, H., Schulze, M. B., Erythrocyte membrane phospholipid polyunsaturated fatty acids are related to plasma C-reactive protein and adiponectin in middle-aged German women and men. Eur J Nutr $2011,50,625-636$. 
[47] Jean-Philippe Bastard, M. M., Claire Lagathu, Min Ji Kim, Martine Caron, Hubert Vidal, Jacqueline Capeau, Bruno Feve, Recent advances in the relationship between obesity, inflammation, and insulin resistance. Eur Cytokine Netw 2006, 17, 4-12.

[48] Muka, T., Kiefte-de Jong, J. C., Hofman, A., Dehghan, A., Rivadeneira, F., Franco, O. H., Polyunsaturated Fatty Acids and Serum C-Reactive ProteinThe Rotterdam Study. Am J Epidemiol $2015,181,846-856$.

[49] Wang, S., Xiang, N., Yang, L., Zhu, C., Zhu, X., Wang, L., Gao, P., Xi, Q., Zhang, Y., Shu, G., Jiang, Q., Linoleic acid and stearic acid elicit opposite effects on AgRP expression and secretion via TLR4-dependent signaling pathways in immortalized hypothalamic N38 cells. Biochem Biophys Res Comm 2016, 471, 566-571.

[50] Hirosumi, J., Tuncman, G., Chang, L., Gorgun, C. Z., Uysal, K. T., Maeda, K., Karin, M., Hotamisligil, G. S., A central role for JNK in obesity and insulin resistance. Nature 2002, 420, 333-336.

[51] Schwartz, M. W., Morton, G. J., Obesity: Keeping hunger at bay. Nature 2002, 418, 595-597.

[52] Delmastro-Greenwood, M., Freeman, B. A., Wendell, S. G., Redox-dependent antiinflammatory signaling actions of unsaturated fatty acids. Annu Rev Physiol 2014, 76, 79-105.

[53] Ameer, F., Scandiuzzi, L., Hasnain, S., Kalbacher, H., Zaidi, N., De novo lipogenesis in health and disease. Metab.: Clin Exp 2014, 63, 895-902.

[54] Diraison, F., Dusserre, E., Vidal, H., Sothier, M., Beylot, M., Increased hepatic lipogenesis but decreased expression of lipogenic gene in adipose tissue in human obesity. Am J Physiol. Endocrinol Metab 2002, 282, E46-51.

[55] Sanders, F. W., Griffin, J. L., De novo lipogenesis in the liver in health and disease: more than just a shunting yard for glucose. Biol Rev 2016, 91, 452-468. 
[56] Chong, M. F., Hodson, L., Bickerton, A. S., Roberts, R., Neville, M., Karpe, F., Frayn, K. N., Fielding, B. A., Parallel activation of de novo lipogenesis and stearoyl-CoA desaturase activity after $3 \mathrm{~d}$ of high-carbohydrate feeding. Am J Clin Nutr 2008, 87, 817-823.

[57] Hudgins, L. C., Seidman, C. E., Diakun, J., Hirsch, J., Human fatty acid synthesis is reduced after the substitution of dietary starch for sugar. Am J Clin Nutr 1998, 67, 631-639.

[58] Weitkunat, K., Schumann, S., Nickel, D., Kappo, K. A., Petzke, K. J., Kipp, A. P., Blaut, M., Klaus, S., Importance of propionate for the repression of hepatic lipogenesis and improvement of insulin sensitivity in high-fat diet-induced obesity. Mol Nutr Food Res 2016.

[59] Singh, V., Yeoh, B. S., Ntambi, J. M., Vijay-Kumar, M., in: Ntambi, M. J. (Ed.), Hepatic De Novo Lipogenesis and Regulation of Metabolism, Springer International Publishing, Cham 2016, pp. 189-209.

[60] Lattka, E., Illig, T., Heinrich, J., Koletzko, B., Do FADS genotypes enhance our knowledge about fatty acid related phenotypes? Clin Nutr2010, 29, 277-287.

[61] Ameur, A., Enroth, S., Johansson, A., Zaboli, G., Igl, W., Johansson, A. C., Rivas, M. A., Daly, M. J., Schmitz, G., Hicks, A. A., Meitinger, T., Feuk, L., van Duijn, C., Oostra, B., Pramstaller, P. P., Rudan, I., Wright, A. F., Wilson, J. F., Campbell, H., Gyllensten, U., Genetic adaptation of fatty-acid metabolism: a human-specific haplotype increasing the biosynthesis of long-chain omega-3 and omega-6 fatty acids. Am J Hum Genet 2012, 90, 809-820.

[62] Keller, M. C., Gene $\times$ Environment Interaction Studies Have Not Properly Controlled for Potential Confounders: The Problem and the (Simple) Solution. Biol Psy 2014, 75, 18-24.

[63] Guan, W., Steffen, B. T., Lemaitre, R. N., Wu, J. H. Y., Tanaka, T., Manichaikul, A., Foy, M., Rich, S. S., Wang, L., Nettleton, J. A., Tang, W., Gu, X., Bandinelli, S., King, I. B., McKnight, B., Psaty, B. M., Siscovick, D., Djousse, L., Ida Chen, Y.-D., Ferrucci, L., Fornage, M., 
Mozafarrian, D., Tsai, M. Y., Steffen, L. M., Genome-Wide Association Study of Plasma N6 Polyunsaturated Fatty Acids Within the Cohorts for Heart and Aging Research in Genomic Epidemiology Consortium. Circ: Cardiovas Genet 2014, 7, 321-331.

[64] Tanaka, T., Shen, J., Abecasis, G. R., Kisialiou, A., Ordovas, J. M., Guralnik, J. M., Singleton, A., Bandinelli, S., Cherubini, A., Arnett, D., Tsai, M. Y., Ferrucci, L., Genome-wide association study of plasma polyunsaturated fatty acids in the InCHIANTI study. PLoS genetics 2009, 5.

[65] Kathiresan, S., Willer, C. J., Peloso, G. M., Demissie, S., Musunuru, K., Schadt, E. E., Kaplan, L., Bennett, D., Li, Y., Tanaka, T., Voight, B. F., Bonnycastle, L. L., Jackson, A. U., Crawford, G., Surti, A., Guiducci, C., Burtt, N. P., Parish, S., Clarke, R., Zelenika, D., Kubalanza, K. A., Morken, M. A., Scott, L. J., Stringham, H. M., Galan, P., Swift, A. J., Kuusisto, J., Bergman, R. N., Sundvall, J., Laakso, M., Ferrucci, L., Scheet, P., Sanna, S., Uda, M., Yang, Q., Lunetta, K. L., Dupuis, J., de Bakker, P. I. W., O'Donnell, C. J., Chambers, J. C., Kooner, J. S., Hercberg, S., Meneton, P., Lakatta, E. G., Scuteri, A., Schlessinger, D., Tuomilehto, J., Collins, F. S., Groop, L., Altshuler, D., Collins, R., Lathrop, G. M., Melander, O., Salomaa, V., Peltonen, L., OrhoMelander, M., Ordovas, J. M., Boehnke, M., Abecasis, G. R., Mohlke, K. L., Cupples, L. A., Common variants at 30 loci contribute to polygenic dyslipidemia. Nat Genet 2009, 41, 56-65.

[66] Jebb, S. A., Cole, T. J., Doman, D., Murgatroyd, P. R., Prentice, A. M., Evaluation of the novel Tanita body-fat analyser to measure body composition by comparison with a fourcompartment model. Br J Nutr 2000, 83, 115-122.

[67] Lloret Linares, C., Ciangura, C., Bouillot, J.-L., Coupaye, M., Declèves, X., Poitou, C., Basdevant, A., Oppert, J.-M., Validity of Leg-to-Leg Bioelectrical Impedance Analysis to Estimate Body Fat in Obesity. Obesity Surg 2011, 21, 917-923. 
602

603

604

605

606

607

608

609

610

611

[68] Browning, L. M., Mugridge, O., Chatfield, M., Dixon, A., Aitken, S., Joubert, I., Prentice, A. M., Jebb, S. A., Validity of a new abdominal bioelectrical impedance device to measure abdominal and visceral fat: comparison with MRI. Obesity 2010, 18, 2385-2391.

[69] Fekete, K., Gyorei, E., Lohner, S., Verduci, E., Agostoni, C., Decsi, T., Long-chain polyunsaturated fatty acid status in obesity: a systematic review and meta-analysis. Obesity Rev $2015,16,488-497$.

[70] Harris, W. S., Pottala, J. V., Varvel, S. A., Borowski, J. J., Ward, J. N., McConnell, J. P., Erythrocyte omega-3 fatty acids increase and linoleic acid decreases with age: observations from 160,000 patients. Prostaglandins Leukot Essent Fatty Acids 2013, 88, 257-263. 
Table 1 Profile of plasma n-6 fatty acids between normal weight, overweight and obese Irish adults (n=781)

\begin{tabular}{|c|c|c|c|c|c|c|c|}
\hline & \multicolumn{2}{|c|}{$\begin{array}{c}\text { Normal weight } \\
(\mathrm{n}=294, \% \text { males }=40.5)\end{array}$} & \multicolumn{2}{|c|}{$\begin{array}{c}\text { Overweight } \\
(n=301, \% \text { males }=58.8)\end{array}$} & \multicolumn{2}{|c|}{$\begin{array}{c}\text { Obese } \\
(\mathrm{n}=186, \% \text { males }=52.2)\end{array}$} & \multirow[t]{2}{*}{ P-trend } \\
\hline & Mean & SD & Mean & SD & Mean & SD & \\
\hline $18: 2 n-6$ & 27.30 & 3.39 & 25.65 & 3.52 & 24.69 & 3.85 & $2.9 \times 10^{-7}$ \\
\hline $18: 3 n-6$ & 0.52 & 0.18 & 0.58 & 0.18 & 0.59 & 0.20 & 0.003 \\
\hline $20: 2 n-6$ & 0.37 & 0.19 & 0.38 & 0.16 & 0.39 & 0.22 & 1.000 \\
\hline $20: 3 n-6$ & 2.02 & 0.47 & 2.02 & 0.47 & 2.11 & 0.47 & 0.003 \\
\hline $20: 4 n-6$ & 7.80 & 1.99 & 7.73 & 1.75 & 7.41 & 1.74 & 0.312 \\
\hline $22: 4 n-6$ & 0.24 & 0.09 & 0.23 & 0.08 & 0.25 & 0.09 & 1.000 \\
\hline D5D & 4.08 & 1.53 & 4.10 & 1.95 & 3.71 & 1.32 & $8.6 \times 10^{-4}$ \\
\hline D6D & 0.020 & 0.01 & 0.024 & 0.01 & 0.025 & 0.01 & $1.6 \times 10^{-5}$ \\
\hline
\end{tabular}

Participants who are under-weight $(\mathrm{n}=5)$ and participants with missing BMI value were excluded from this analysis ( $\mathrm{n}=34)$. D5D: delta-5-desaturase (20:4n6/20:3n6); D6D: delta-6-desaturase (18:3n6/18:2n6).

General linear contrast model adjusted for age and gender was used, P-values were corrected by multiple number of traits. Pvalues that exceed 1.0 after correction for multiple testing have been marked down to 1.000 .

614

615

616 
Table 2. Demographics across quartiles of plasma linoleic acid in Irish adults $(\mathrm{n}=820)$.

\begin{tabular}{|c|c|c|c|c|c|c|c|c|c|}
\hline & \multicolumn{8}{|c|}{ Quartiles of plasma linoleic acid } & \multirow{4}{*}{ P-trend } \\
\hline & \multirow{2}{*}{\multicolumn{2}{|c|}{$\begin{array}{c}1(\mathrm{n}=205) \\
\% \mathrm{LA}=21.1\end{array}$}} & \multirow{2}{*}{\multicolumn{2}{|c|}{$\begin{array}{c}2(\mathrm{n}=205) \\
\% \mathrm{LA}=25.0\end{array}$}} & \multirow{2}{*}{\multicolumn{2}{|c|}{$\begin{array}{c}3(n=205) \\
\% \mathrm{LA}=27.4\end{array}$}} & \multirow{2}{*}{\multicolumn{2}{|c|}{$\begin{array}{c}4(\mathrm{n}=205) \\
\% \mathrm{LA}=30.5\end{array}$}} & \\
\hline & & & & & & & & & \\
\hline & Mean & SD & Mean & SD & Mean & SD & Mean & SD & \\
\hline Age (years) & 50.67 & 17.00 & 42.31 & 16.89 & 38.04 & 15.06 & 36.46 & 14.02 & $1.9 \times 10^{-19}$ \\
\hline BMI $\left(\mathrm{kg} / \mathrm{m}^{2}\right)$ & 29.02 & 5.75 & 27.07 & 4.99 & 26.66 & 4.60 & 25.30 & 3.73 & $2.2 \times 10^{-12}$ \\
\hline Body fat (\%) & 31.46 & 10.12 & 28.66 & 9.16 & 28.68 & 8.66 & 26.32 & 8.74 & $3.1 \times 10^{-6}$ \\
\hline Waist circumference (cm) & 97.83 & 15.27 & 91.05 & 13.76 & 90.00 & 12.95 & 85.56 & 11.54 & $1.2 \times 10^{-15}$ \\
\hline Waist hip ratio & 0.92 & 0.09 & 0.87 & 0.09 & 0.86 & 0.08 & 0.85 & 0.07 & $3.5 \times 10^{-13}$ \\
\hline Systolic blood pressure (mmHg) & 131.93 & 18.12 & 123.86 & 16.03 & 122.22 & 17.38 & 118.23 & 15.12 & $1.7 \times 10^{-13}$ \\
\hline Diastolic blood pressure (mmHg) & 81.44 & 11.13 & 78.05 & 10.43 & 76.86 & 10.69 & 75.34 & 9.97 & $2.2 \times 10^{-7}$ \\
\hline \multicolumn{10}{|l|}{ Physical activity (MET hrs/wk) } \\
\hline Work activities & 47.77 & 60.31 & 58.88 & 52.81 & 62.70 & 58.90 & 66.08 & 70.89 & 0.026 \\
\hline Recreational activities & 27.55 & 41.01 & 37.64 & 51.90 & 38.37 & 56.67 & 34.12 & 39.37 & 1.000 \\
\hline Gender & \multicolumn{2}{|c|}{$\mathrm{M}=118, \mathrm{~F}=87$} & \multicolumn{2}{|c|}{$\mathrm{M}=105, \mathrm{~F}=100$} & \multicolumn{2}{|c|}{$\mathrm{M}=93, \mathrm{~F}=112$} & \multicolumn{2}{|c|}{$\mathrm{M}=96, \mathrm{~F}=109$} & 0.061 \\
\hline Oral contraceptive users (\%) & \multicolumn{2}{|c|}{2.9} & \multicolumn{2}{|c|}{2.4} & \multicolumn{2}{|c|}{6.3} & \multicolumn{2}{|c|}{2.4} & 0.094 \\
\hline Metabolic risk factor $(\%)$ & & & & & & & & & $3.7 \times 10^{-20}$ \\
\hline No Risk Factors & \multicolumn{2}{|c|}{18.0} & \multicolumn{2}{|c|}{39.0} & \multicolumn{2}{|c|}{46.3} & \multicolumn{2}{|c|}{60.5} & \\
\hline 1-2 Risk Factors & \multicolumn{2}{|c|}{53.2} & \multicolumn{2}{|c|}{48.3} & \multicolumn{2}{|c|}{47.3} & \multicolumn{2}{|c|}{27.8} & \\
\hline$>3$ Risk Factors & \multicolumn{2}{|c|}{22.0} & \multicolumn{2}{|c|}{8.8} & \multicolumn{2}{|c|}{4.9} & \multicolumn{2}{|c|}{4.9} & \\
\hline Smoking status $(\%)$ & & & & & & & & & 0.001 \\
\hline Current smoker & 22 & & 18 & & 21 & & 18 & & \\
\hline Former smoker & 36. & & 27 & & 21 & & 18 & & \\
\hline Never smoke & 41 & & 53 & & 57 & & 62 & & \\
\hline Social class $(\%)$ & & & & & & & & & 0.153 \\
\hline Professional/managerial/technical & 48. & & 46 & & 42 & & 43 & & \\
\hline Non-manual skilled & 12 . & & 17 & & 19 & & 18 & & \\
\hline Manual skilled & 21 & & 13 & & 11 & & 14 & & \\
\hline Semi-skilled/unskilled & 17 & & 22 & & 25 & & 24 & & \\
\hline Weight class & & & & & & & & & $2.7 \times 10^{-7}$ \\
\hline Normal weight & 20 & & 37 & & 38 & & 53 & & \\
\hline Overweight & 45 . & & 37 & & 39 & & 32 & & \\
\hline Obese & 34. & & 24 & & 22 & & 14 & & \\
\hline
\end{tabular}

Comparisons of age, BMI, body fat, waist circumference, physical activity and blood pressure across quartiles were assessed using Linear contrast analysis; comparisons of gender, smoking status, social class, weight class and metabolic risk factor were based on chi square statistic.P-values were corrected by multiple number of traits. P-values that exceed 1.0 after correction for multiple testing have been marked down to 1.000. M: males; F: females.

617 
Table 3. Concentration of biochemistry biomarkers across quartiles of plasma linoleic acid in Irish adults ( $\mathrm{n}=820)$.

\begin{tabular}{|c|c|c|c|c|c|c|c|c|c|}
\hline & \multicolumn{9}{|c|}{ Quartiles of plasma linoleic acid } \\
\hline & \multirow{2}{*}{\multicolumn{2}{|c|}{$\begin{array}{c}1(\mathrm{n}=205) \\
\% \mathrm{LA}=21.1\end{array}$}} & \multirow{2}{*}{\multicolumn{2}{|c|}{$\begin{array}{c}2(\mathrm{n}=205) \\
\% \mathrm{LA}=25.0\end{array}$}} & \multirow{2}{*}{\multicolumn{2}{|c|}{$\begin{array}{c}3(n=205) \\
\% \mathrm{LA}=27.4\end{array}$}} & \multirow{2}{*}{\multicolumn{2}{|c|}{$\begin{array}{c}4(\mathrm{n}=205) \\
\% \mathrm{LA}=30.5\end{array}$}} & \multirow[t]{3}{*}{ P-trend } \\
\hline & & & & & & & & & \\
\hline & Mean & SD & Mean & $\mathrm{SD}$ & Mean & $\mathrm{SD}$ & Mean & $\mathrm{SD}$ & \\
\hline \multicolumn{10}{|l|}{ Metabolism } \\
\hline Glucose (mmol/l) & 5.71 & 1.21 & 5.23 & 1.28 & 5.11 & 0.66 & 5.03 & 0.86 & 0.058 \\
\hline Insulin $(\mu \mathrm{IU} / \mathrm{ml})$ & 12.77 & 10.80 & 8.73 & 6.15 & 8.97 & 8.08 & 7.48 & 5.28 & $5.7 \times 10^{-5}$ \\
\hline C-Peptide (ng/ml) & 3.00 & 2.51 & 2.08 & 2.41 & 1.93 & 1.97 & 1.48 & 1.40 & $7.0 \times 10^{-5}$ \\
\hline Triglyceride (mmol/l) & 1.83 & 0.88 & 1.28 & 0.58 & 1.03 & 0.38 & 0.86 & 0.33 & $2.1 \times 10^{-35}$ \\
\hline Total Cholesterol (mmol/l) & 5.02 & 1.10 & 5.02 & 0.93 & 4.96 & 1.01 & 4.75 & 0.94 & 1.000 \\
\hline LDL Cholesterol (mmol/1) & 2.72 & 0.93 & 2.90 & 0.79 & 2.89 & 0.92 & 2.76 & 0.80 & 0.160 \\
\hline HDL Cholesterol (mmol/l) & 1.47 & 0.41 & 1.54 & 0.41 & 1.60 & 0.43 & 1.59 & 0.42 & 1.000 \\
\hline HOMA-IR & 3.43 & 3.76 & 2.09 & 1.74 & 2.16 & 2.59 & 1.71 & 1.33 & $9.1 \times 10^{-6}$ \\
\hline QUICKI & 0.34 & 0.04 & 0.36 & 0.04 & 0.36 & 0.04 & 0.37 & 0.04 & $1.9 \times 10^{-5}$ \\
\hline \multicolumn{10}{|c|}{ Immune function and metabolic health } \\
\hline PAI-1 (ng/ml) & 25.46 & 9.16 & 24.00 & 9.68 & 22.11 & 8.60 & 20.29 & 7.08 & $1.2 \times 10^{-4}$ \\
\hline TNF- $\alpha(\mathrm{pg} / \mathrm{ml})$ & 7.60 & 2.70 & 6.99 & 2.60 & 6.66 & 2.48 & 6.28 & 1.55 & 0.005 \\
\hline High Sensitivity CRP (mg/l) & 3.49 & 3.27 & 2.84 & 3.00 & 2.35 & 2.40 & 2.08 & 2.09 & 0.003 \\
\hline Adiponectin $(\mu \mathrm{g} / \mathrm{ml})$ & 5.16 & 2.69 & 5.78 & 3.28 & 6.52 & 3.28 & 6.35 & 3.13 & 0.002 \\
\hline Leptin Soluble Receptor (ng/ml) & 27.16 & 6.76 & 27.19 & 7.24 & 27.48 & 7.21 & 27.49 & 6.27 & 1.000 \\
\hline Resistin(ng/ml) & 5.92 & 2.50 & 6.30 & 2.88 & 6.01 & 2.64 & 6.04 & 2.72 & 1.000 \\
\hline \multicolumn{10}{|l|}{ Plasma fatty acids (\%) and desaturase } \\
\hline Total n-6 PUFA & 32.1 & 2.99 & 36.1 & 2.02 & 38.38 & 1.93 & 41.04 & 2.32 & $1.4 \times 10^{-138}$ \\
\hline $18: 2 n-6$ & 21.07 & 2.03 & 25.02 & 0.78 & 27.36 & 6.17 & 30.50 & 1.86 & $4.0 \times 10^{-252}$ \\
\hline $20: 2 n-6$ & 0.44 & 0.25 & 0.37 & 0.15 & 0.35 & 0.17 & 0.35 & 0.13 & $1.9 \times 10^{-7}$ \\
\hline $18: 3 n-6$ & 0.62 & 0.20 & 0.58 & 0.17 & 0.54 & 0.18 & 0.51 & 0.17 & $8.8 \times 10^{-5}$ \\
\hline $20: 3 n-6$ & 2.05 & 0.49 & 2.13 & 0.49 & 2.02 & 0.46 & 1.97 & 0.42 & 0.019 \\
\hline $20: 4 n-6$ & 7.62 & 2.18 & 7.71 & 1.72 & 7.89 & 1.79 & 7.49 & 1.64 & 1.000 \\
\hline $22: 4 n-6$ & 0.25 & 0.09 & 0.24 & 0.08 & 0.23 & 0.09 & 0.23 & 0.08 & 0.156 \\
\hline EPA & 1.56 & 1.00 & 1.43 & 0.78 & 1.32 & 0.80 & 1.18 & 0.70 & 1.000 \\
\hline DHA & 2.42 & 0.97 & 2.47 & 0.93 & 2.44 & 0.93 & 2.25 & 0.85 & 1.000 \\
\hline D5D & 3.95 & 1.68 & 3.82 & 1.30 & 4.18 & 2.09 & 4.01 & 1.40 & 1.000 \\
\hline D6D & 0.03 & 0.01 & 0.02 & 0.01 & 0.02 & 0.01 & 0.02 & 0.01 & $4.7 \times 10^{-35}$ \\
\hline n-6/n-3 ratio & 5.96 & 1.64 & 6.72 & 1.67 & 7.59 & 2.50 & 8.43 & 2.26 & $1.2 \times 10^{-17}$ \\
\hline Total SFA & 37.16 & 3.50 & 35.77 & 3.07 & 34.65 & 2.77 & 33.63 & 2.81 & $6.0 \times 10^{-32}$ \\
\hline Total MUFA & 24.94 & 3.63 & 22.41 & 3.60 & 21.42 & 3.14 & 20.07 & 3.13 & $1.1 \times 10^{-21}$ \\
\hline $14: 0$ & 1.47 & 0.44 & 1.19 & 0.31 & 1.01 & 0.32 & 0.93 & 0.26 & $7.8 \times 10^{-30}$ \\
\hline $16: 0$ & 24.48 & 1.96 & 23.20 & 1.45 & 22.50 & 1.35 & 21.56 & 1.18 & $9.1 \times 10^{-53}$ \\
\hline 18:0 & 9.86 & 2.61 & 9.97 & 2.62 & 9.82 & 2.59 & 9.80 & 2.49 & 0.288 \\
\hline
\end{tabular}




\begin{tabular}{cccccccccc}
$14: \ln -5$ & 0.14 & 0.07 & 0.10 & 0.05 & 0.08 & 0.05 & 0.06 & 0.04 & $4.0 \times 10^{-30}$ \\
$16: \ln -7$ & 3.43 & 0.94 & 2.71 & 0.61 & 2.30 & 0.48 & 1.88 & 0.49 & $7.5 \times 10^{-71}$ \\
$18: \ln -9$ & 20.38 & 3.52 & 18.60 & 3.49 & 18.08 & 3.11 & 17.20 & 3.07 & $4.7 \times 10^{-6}$ \\
\hline
\end{tabular}

Comparisons of concentration of biochemical biomarkers and plasma fatty acids (log transformed for skewed variable) across quartiles were assessed using General Linear Contrast Model adjusted for age, body fat, blood pressure, waist circumference, waist hip ratio, smoking status, working energy expenditure and BMI. P-values were corrected by multiple number of traits. P-values that exceed 1.0 after correction for multiple testing have been marked down to 1.000. QUICKI: quantitative insulin sensitivity check index; PAI-1: plasminogen activator inhibitor-1; hs-CRP: high-sensitivity-C-reactive protein; D5D: delta-5-desaturase (20:4n6/20:3n6); D6D: delta-6-desaturase (18:3n6/18:2n6). 
Table 4. Haplotype characteristics of 15-locus, 8-locus and 3-locus haplotypes ( $\mathrm{n}=790)$.

\begin{tabular}{lcccc}
\hline & Haplotypes & Alleles ${ }^{\text {a }}$ & $\begin{array}{c}\text { Number of minor } \\
\text { allele }\end{array}$ & Frequency \\
\hline 15-locus haplotype (rs174537 to rs482548) & & & \\
Haplo1 & TTGTCTTTCGAATGC & 222222221211221 & 11 & $17.0 \%$ \\
Haplo2 & GCCCTCCCCCAACCT & 111111111111112 & 1 & $11.1 \%$ \\
Haplo3 & TTGTCTCTCGTGTCC & 222222121222211 & 11 & $2.3 \%$ \\
Haplo4 & TTGTCTCTTCTGTCC & 222222122122211 & 11 & $7.1 \%$ \\
Haplo5 & TTCCTTCTTGAATGC & 221112122211221 & 8 & $3.0 \%$ \\
Haplo6 & TTGTCTCTTGAATGC & 222222122211221 & 11 & $1.6 \%$ \\
Haplo7 & GCCCTCCCCCAACCC & 11111111111111 & 0 & $53.9 \%$ \\
8-locus haplotype (rs174537 to rs99780) & & & \\
Haplo1 & TTGTCTTT & 22222222 & 8 & $19.2 \%$ \\
Haplo2 & TTGTCTCT & 22222212 & 7 & $11.4 \%$ \\
Haplo3 & TTCCTTCT & 22111212 & 4 & $3.0 \%$ \\
Haplo4 & GCCCTCCC & 11111111 & 0 & $65.6 \%$ \\
\multicolumn{2}{l}{ 3-locus haplotype (rs2524299 to rs174583) } \\
Haplo1 & TGT & & & \\
Haplo2 & AAT & 222 & 3 & $10.9 \%$ \\
Haplo3 & AAC & 112 & 1 & $22.8 \%$ \\
\hline
\end{tabular}

${ }^{\mathrm{a}} 1$, major allele; 2 , minor allele. 
Table 5. Estimates of haplotypes effects on plasma linoleic acid, $\Delta-5$ desaturase and $\Delta-6$ desaturase $(\mathrm{n}=790)$.

\begin{tabular}{|c|c|c|c|c|c|c|}
\hline & \multicolumn{2}{|c|}{ Plasma LA } & \multicolumn{2}{|c|}{$\Delta-5$ desaturase } & \multicolumn{2}{|c|}{$\Delta-6$ desaturase } \\
\hline & Estimates $\pm \mathrm{SE}$ & $P$ value & Estimates $\pm \mathrm{SE}$ & $P$ value & Estimates $\pm \mathrm{SE}$ & $\mathrm{P}$ value \\
\hline \multicolumn{7}{|c|}{ 15-locus haplotype } \\
\hline Haplo1 & $0.82 \pm 0.24$ & $7.1 \times 10^{-4}$ & $-0.99 \pm 0.11$ & $1.81 \times 10^{-19}$ & $-0.004 \pm 0.001$ & $4.4 \times 10^{-9}$ \\
\hline Haplo2 & $0.25 \pm 0.28$ & 0.37 & $-0.10 \pm 0.13$ & 0.446 & $-0.001 \pm 0.001$ & 0.211 \\
\hline Haplo3 & $1.31 \pm 0.53$ & 0.01 & $-0.86 \pm 0.25$ & $6.37 \times 10^{-4}$ & $-0.006 \pm 0.001$ & $5.5 \times 10^{-5}$ \\
\hline Haplo4 & $0.77 \pm 0.34$ & 0.02 & $-0.81 \pm 0.15$ & $1.21 \times 10^{-7}$ & $-0.005 \pm 0.001$ & $1.1 \times 10^{-9}$ \\
\hline Haplo5 & $1.74 \pm 0.51$ & $6.9 \times 10^{-4}$ & $-0.34 \pm 0.23$ & 0.146 & $-0.006 \pm 0.001$ & $4.9 \times 10^{-6}$ \\
\hline Haplo6 & $0.94 \pm 0.70$ & 0.18 & $-0.87 \pm 0.32$ & $6.44 \times 10^{-3}$ & $-0.006 \pm 0.002$ & $4.9 \times 10^{-4}$ \\
\hline \multicolumn{7}{|c|}{ 8-locus haplotype } \\
\hline Haplo1 & $0.78 \pm 0.22$ & $4.06 \times 10^{-4}$ & $-1.02 \pm 1.00$ & $2.45 \times 10^{-24}$ & $-0.003 \pm 0.001$ & $8.9 \times 10^{-10}$ \\
\hline Haplo2 & $0.91 \pm 0.27$ & $6.86 \times 10^{-4}$ & $-0.85 \pm 0.01$ & $4.27 \times 10^{-12}$ & $-0.005 \pm 0.001$ & $6.4 \times 10^{-15}$ \\
\hline Haplo3 & $1.59 \pm 0.50$ & $1.67 \times 10^{-3}$ & $-0.32 \pm 0.50$ & $1.67 \times 10^{-3}$ & $-0.006 \pm 0.002$ & $8.8 \times 10^{-6}$ \\
\hline \multicolumn{7}{|c|}{ 3-locus haplotype } \\
\hline Haplo1 & $0.86 \pm 0.27$ & $1.64 \times 10^{-3}$ & $-0.85 \pm 0.13$ & $2.34 \times 10^{-11}$ & $-0.004 \pm 0.001$ & $2.4 \times 10^{-12}$ \\
\hline Haplo2 & $0.90 \pm 0.20$ & $1.03 \times 10^{-5}$ & $-0.88 \pm 0.09$ & $5.34 \times 10^{-21}$ & $-0.004 \pm 0.002$ & $4.7 \times 10^{-14}$ \\
\hline
\end{tabular}

The most common haplotype was used as reference.

Maximum likelihood estimation adjusted for age, BMI, body fat, waist circumference, working energy expenditure, waist hip ratio, blood pressure and smoking habits was used. 
Table 6. Multiple linear regression analysis of possible plasma linoleic acid determinates with 15 locus haplotype $(\mathrm{n}=790)$.

\begin{tabular}{lcccc}
\hline & $\beta$ Coefficient & Standard error & $\mathrm{P}$ & $\begin{array}{c}\text { Variance } \\
\text { explained }\end{array}$ \\
\hline Age (years) & -0.047 & 0.010 & $<0.001$ & $3.2 \%$ \\
Waist circumference (cm) & -0.036 & 0.012 & 0.002 & $8.1 \%$ \\
PUFA intakes (\%TE) & 0.325 & 0.065 & $<0.001$ & $3.7 \%$ \\
Fibre intakes (g/10MJ) & 0.035 & 0.019 & 0.066 & $0.5 \%$ \\
Systolic blood pressure (mmHg) & -0.028 & 0.010 & 0.002 & $3.6 \%$ \\
Body fat (\%) & -0.040 & 0.017 & 0.020 & $3.7 \%$ \\
Sugar intakes (\%TE) & -0.090 & 0.032 & 0.005 & $1.3 \%$ \\
Carbohydrate intakes (\%TE) & 0.098 & 0.027 & $<0.001$ & $2.0 \%$ \\
15-locus Haplotype ${ }^{\text {a }}$ & & & & $3.9 \%$ \\
Haplo1 & 0.796 & 0.253 & 0.002 & \\
Haplo2 & 0.455 & 0.305 & 0.136 & \\
Haplo3 & 1.843 & 0.604 & 0.002 & \\
Haplo4 & 1.011 & 0.345 & 0.003 & \\
Haplo5 & 1.177 & 0.569 & 0.039 & \\
Haplo6 & 0.893 & 0.817 & 0.275 & \\
\hline
\end{tabular}

${ }^{a}$ Most common haplotype was used as a reference 